\title{
Aggressive pituitary tumours and carcinomas: two sides of the same coin?
}

\author{
Jacqueline Trouillas', Pia Burman ${ }^{2,3}$, Ann McCormack ${ }^{4,5}$, Stephan Petersenn ${ }^{6}$, Vera Popovic ${ }^{7}$, Olaf Dekkers ${ }^{8}$ and \\ Gerald Raverot ${ }^{1,9}$
}

${ }^{1}$ Faculté de Médecine Lyon Est, Université Lyon 1, Lyon, France, ${ }^{2}$ Endocrinology, Skåne University Hospital, Malmo, Sweden, ${ }^{3}$ Endocrinology, University of Lund, Malmo, Sweden, ${ }^{4}$ Department of Endocrinology, St Vincent's Hospital, Sydney, New South Wales, Australia, ${ }^{5}$ Hormones and Cancer Group, Garvan Institute of Medical Research, Sydney, New South Wales, Australia, ${ }^{6}$ Center for Endocrine Tumors, ENDOC, Hamburg, Germany, ${ }^{7}$ School of Medicine, University of Belgrade, Belgrade, Serbia, ${ }^{8}$ Departments of Clinical Epidemiology and Endocrinology, Leids Universitair Medisch Centrum Ringgold Standard Institution, Leiden, Zuid-Holland, Netherlands, and ${ }^{9}$ Fédération d'Endocrinologie, Centre de Référence des Maladies Rares Hypophysaires HYPO, Hospices Civils de Lyon, Bron, France

Correspondence should be addressed to G Raverot

Email

gerald.raverot@chu-lyon.fr

\begin{abstract}
The European Society of Endocrinology (ESE) survey reported on the largest cohort of 125 aggressive pituitary tumours (APT) and 40 pituitary carcinomas (PC). Whilst the survey focused on treatment effectiveness, all pathological data were not explored in detail. Here, we comment on some interesting pathological findings, notably the difference between APT and PC.
\end{abstract}

\section{Introduction}

For a pituitary pathologist, the cohort of 125 aggressive pituitary tumours (APTs) and 40 pituitary carcinomas (PCs) of the European Society of Endocrinology (ESE) survey is clearly a 'gold mine', by far the largest series thus far. As this study, recently published in EJE (1), mainly focused on treatment effectiveness, not all pathological data were explored in full detail. Here, we would like to comment on some interesting pathological findings, especially regarding the difference between APT and PC.

\section{Comment}

The ESE collaborative study demonstrated a high degree of similarity between the 125 APTs, defined as 'an invasive tumour with rapid growth, multiple recurrences and resistance to standard therapies' and the 40 PCs with metastatic disease. Clinically, the sex ratio, percentage of corticotroph tumours, percentage of tumours with Ki-67 index $\geq 3 \%$, percentage with elevated mitotic count $\mathrm{n} \geq 2 / 10 \mathrm{HPF}$ and p53 expression, respectively, as well as

www.eje-online.org https://doi.org/10.1530/EJE-18-0250
(C) 2018 European Society of Endocrinology Printed in Great Britain time-to-death after the diagnosis were similar between the two groups (APT means 11 years, range 4-31; PC 12 years, range 1-26). However, mortality was higher in PC than APT patients, Fig. 1.

Here, we explore whether our survey cohort of aggressive pituitary tumours (henceforth APT $+\mathrm{PC}$ cohort) differed from series of pituitary tumours unselected for their aggressive behaviour. We compare the survey's results with two large series of surgically treated pituitary tumours, recently published $(2,3)$. In those series, gonadotroph or non-functioning tumours were the most frequent subtypes (47-50\%) but were uncommon in the $\mathrm{APT}+\mathrm{PC}$ cohort $(18 \%)$. In contrast, corticotroph tumours were rare in surgical series (about 15\%), but common (45\%) in the APT+PC cohort. More importantly, in the Lyon cohort (2) in whom the two proliferative markers were systematically tested in 365 tumours, the Ki-67 index was $\geq 3 \%$ in only $23.5 \%$ of all tumours compared to $82.5 \%$ in the APT+PC cohort. A Ki-67 index $\geq 10 \%$, considered a sign of malignancy, was found in $46 \%$ of the APT + PC cohort, without distinction between APT or PC,

Published by Bioscientifica Ltd. 
but is exceptional in other series. Furthermore, tumours displaying positivity for all three markers (Ki67 $\geq 3 \%$, positive P53, mitotic rate $>2 / 10 \mathrm{HPF}$ ) represent about $2 \%$ of all types (2) and $56 \%$ in the APT+PC cohort. In short, surgically treated, but otherwise unselected, pituitary tumours have clinically and pathologically distinct features.

Are malignant pituitary tumours rare? If only tumours with metastasis are considered they are very rare, accounting for just $0.2 \%$ of all pituitary tumours. The prevalence of APT is not well known. The frequency of Grade $2 b$ pituitary tumours (invasive with high proliferation) is around 10\% (4). However, not all Grade $2 \mathrm{~b}$ tumours will develop clinically aggressive behaviour. Nevertheless, as has been demonstrated, APT and PC are clinically and histologically similar, so we suggest that APTs are 'tumours with malignant potential without metastasis'. It is one of the reasons why it has been proposed to change the term pituitary adenomas to Pituitary NeuroEndocrine Tumours (PitNET) (5). However, it must be underlined that the majority of pituitary tumours (50$60 \%$ ) are benign (adenomas) and that the great majority of malignant tumours remain well differentiated. We propose the following diagram (Fig. 2) of pituitary tumour behaviour, knowing that hyperplasia was never observed before or associated with tumour formation and assuming that the great majority of patients are cured or controlled by surgery, with or without radiotherapy or standard medical therapies.

\section{Conclusion}

In conclusion, the diagnosis of a malignant pituitary tumour remains difficult. Given that both APT and PC result

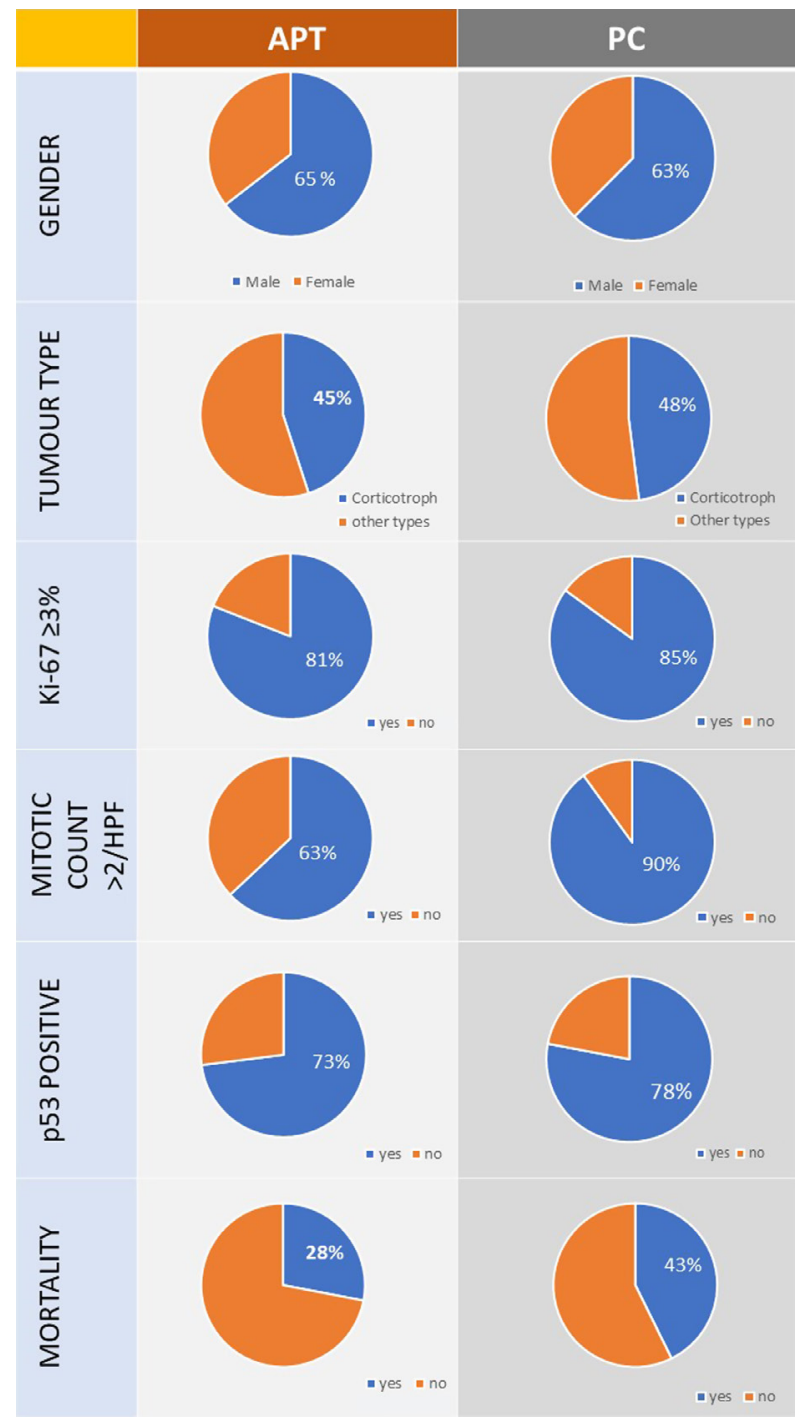

Figure 1

Similarities between the 125 aggressive pituitary tumors (APT) and the 40 pituitary carcinomas (PC).

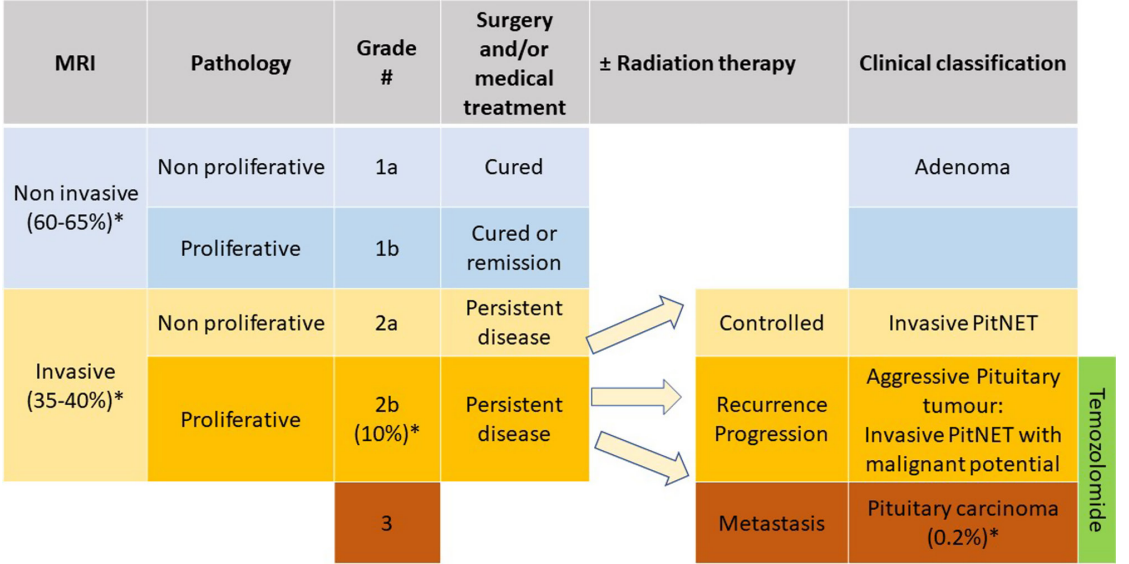

\section{Figure 2}

Diagram representing potential pituitary neuroendocrine tumour (PitNET) behaviours. 
in premature death as a result of tumour progression, we propose that an aggressive pituitary tumour is considered a tumour with malignant potential. The management of these patients must be multidisciplinary, with a dialogue between the endocrinologist, the neurosurgeon and the pathologist.

Declaration of interest

The authors declare that there is no conflict of interest that could be perceived as prejudicing the impartiality of this commentary.

\section{Funding}

This work did not receive any specific grant from any funding agency in the public, commercial, or not-for-profit sector.

\section{References}

1 McCormack A, Dekkers OM, Petersenn S, Popovic V, Trouillas J, Raverot G, Burman P \& on behalf of the ESE survey collaborators.
Treatment of aggressive pituitary tumours and carcinomas: results of a European Society of Endocrinology (ESE) survey 2016. European Journal of Endocrinology 2018178 265-276. (https://doi.org/10.1530/ EJE-17-0933)

2 Raverot G, Dantony E, Beauvy J, Vasiljevic A, Mikolasek S, BorsonChazot F, Jouanneau E, Roy P \& Trouillas J. Risk of recurrence in pituitary neuroendocrine tumors: a prospective study using a five-tiered classification. Journal of Clinical Endocrinology and Metabolism 2017102 3368-3374. (https://doi.org/10.1210/ jc.2017-00773)

3 Mete O, Cintosun A, Pressman I \& Asa SL. Epidemiology and biomarker profile of pituitary adenohypophysial tumors. Modern Pathology 2018. (https://doi.org/10.1038/s41379-018-0016-8)

4 Trouillas J, Roy P, Sturm N, Dantony E, Cortet-Rudelli C, Viennet G, Bonneville JF, Assaker R, Auger C, Brue T et al. A new prognostic clinicopathological classification of pituitary adenomas: a multicentric case-control study of 410 patients with 8 years postoperative follow-up. Acta Neuropathologica 2013126 123-135. (https://doi.org/10.1007/s00401-013-1084-y)

5 Asa SL, Casar-Borota O, Chanson P, Delgrange E, Earls P, Ezzat S, Grossman A, Ikeda H, Inoshita N, Karavitaki N et al. From pituitary adenoma to pituitary neuroendocrine tumor (PitNET): an International Pituitary Pathology Club proposal. Endocrine Related Cancer 201724 C5-C8. (https://doi.org/10.1530/ERC-170004)

Received 25 March 2018

Accepted 26 March 2018 